\title{
Design specification for Beam Containment System Ion Chamber Gas Systems
}

September 17, 2012

An ad-hoc committee was convened on 30 August 2012 to provide a recommendation for new BCS ionization chamber gas systems. The members are:

- Mao, Stan - RP and convener

- Bennett, Brian - Safety Sections/BCS

- $\quad$ Field, Clive - ICD Physicist

- Gioumousis, Andrew - Safety Sections/BCS

- Jobe, Keith - Test Facilities and author

- Miller, Paul - ADSO

- Nicolas, Ludovic - RP

- Van Hoover, Zoe - ADSO

This recommendation serves as a design guide for new or modified gas systems used for Beam Containment System (BCS) ionization chambers.

Ionization chambers are used at SLAC as protection devices near collimators, dumps and areas where beam loss must be limited through engineering controls. The two detector technologies considered in this note are Protection Ionization Chambers (PICs) and Long Ionization Chambers (LIONs).

The ionization chambers are typically installed in redundant pairs and are set by introducing a controlled beam loss and using the measurements to determine a trip current setting. As such, the trip setting for any installation is specific to the system and is usually reestablished following any change in the system (change of gas, operating pressure, detector placement).

\section{Committee Recommendations:}

Gas system topology:

- Gas should flow through all ionization chambers in a system or subsystem. Individual chambers are connected in series. PICs and LIONs may be installed on the same system.

- $\quad$ PIC or LION style ionization chambers used for non-BCS purposes (e.g.: beam diagnostics or machine protection) may be included in the BCS gas system ${ }^{1}$.

- The gas system is a single-pass distribution with a continuous purge. The purge rate should be sufficient to replace the gas in all system components at a rate of at least one volume change per week.

- Ionization chambers should be set to operate at a positive pressure of eight (8) pounds per square inch above atmospheric pressure (8 PSIG). Pressure may be adjusted to the design pressure during servicing, maintenance or repair opportunities. Deviation in pressure during operation of plus or minus two (2) pounds per square inch is considered acceptable.

- Gauges or sensors used to monitor or set system pressure must be of good industrial quality. NIST traceability is not required in BCS pressure monitoring systems.

- Tubing and gas fittings may be of any material compatible with the detector gas, including stainless steel, copper, aluminum, brass, polyethylene, or polyurethane.

- The final pressure regulator, purge valves, pressure interlock switches and system critical controls shall be in a locked cabinet under the control of the Safety Section. High pressure gas systems and gas delivery components, including the 6-pack and tank pressure regulator, may be in an uncontrolled environment.

\footnotetext{
${ }^{1}$ The safety systems configuration control (RSWCFs, etc.) apply to non-safety systems connected to BCS gas systems. Prior to the use of the BCS gas system to non-safety applications, concurrence from the Accelerator Department Safety Office and the BCS group must be obtained.
} 


\section{SLAC morome

- Non-radiological hazards of gas system installation must be included in system design. Of particular note is the possibility of creating a localized Oxygen Deficiency Hazard following the failure of an ionization chamber vessel or gas fitting.

Gas system interlocks

- Two redundant gas pressure switches shall monitor the system pressure. Both interlock switches shall be in the BCS gas cabinet. At least one switch is located at the end of the gas flow (near the purge point).

- An interlock fault will be generated when the pressure drops to below four (4) pounds per square inch (4 PSIG). Interlock pressure is adjusted to the design pressure during servicing, maintenance or repair opportunities. Deviation in pressure during operation of plus or minus two (2) pound per square inch is considered acceptable.

\section{Gas Species}

- The standard gas for BCS ionization chambers is 5\% carbon dioxide 95\% argon obtained as a premixed gas.

- Alternate gas choices of pure nitrogen or "chemical air" (21\% oxygen balance argon or nitrogen) may be considered in deployments where oxygen deficiency hazards cannot be adequately addressed through the use of flow restricting orifices or other passive technologies. 


\section{Design of Gas System:}

The key components of the gas system are:

- Gas source, typically a vendor supplied 6-pack of gas containing 1,200 to 1,800 cubic feet of gas at approximately 2,000 PSIG.

- Spare gas source, typically a second 6-pack of gas located near the main gas source.

- Pressure sensor connected to the SLAC Operations/Facilities Distributed Control System (DCS) to monitor tank pressure and facilitate replacement of gas. The DCS sensor is not part of the BCS safety system.

- Gas pressure regulator with pressure relief valve. Pressure regulators with integrated pressure relief valves are acceptable. The pressure relief valve must be set to less than the maximum allowable pressure of any component in the system.

- $\quad$ BCS gas panel is in a lockable enclosure. The BCS gas panel contains:

- Pressure gauges and valves as required.

- Flow restricting orifice. The orifice may not be required if an analysis demonstrated that the ventilation of all areas containing piping or chambers is free from the potential development of an oxygen deficiency hazard. See section on gases for further toxicity and ODH considerations..

- Pressure regulator set to provide ionization chambers with the desired gas pressure.

- Pressure switches set to fault (open) if the pressure drops below the interlock pressure.

- Controlled purge valve with flow indicating device (e.g. a rotameter).

- Uncontrolled purge valve for system flushing.

- Ionization chambers plumbed in series.

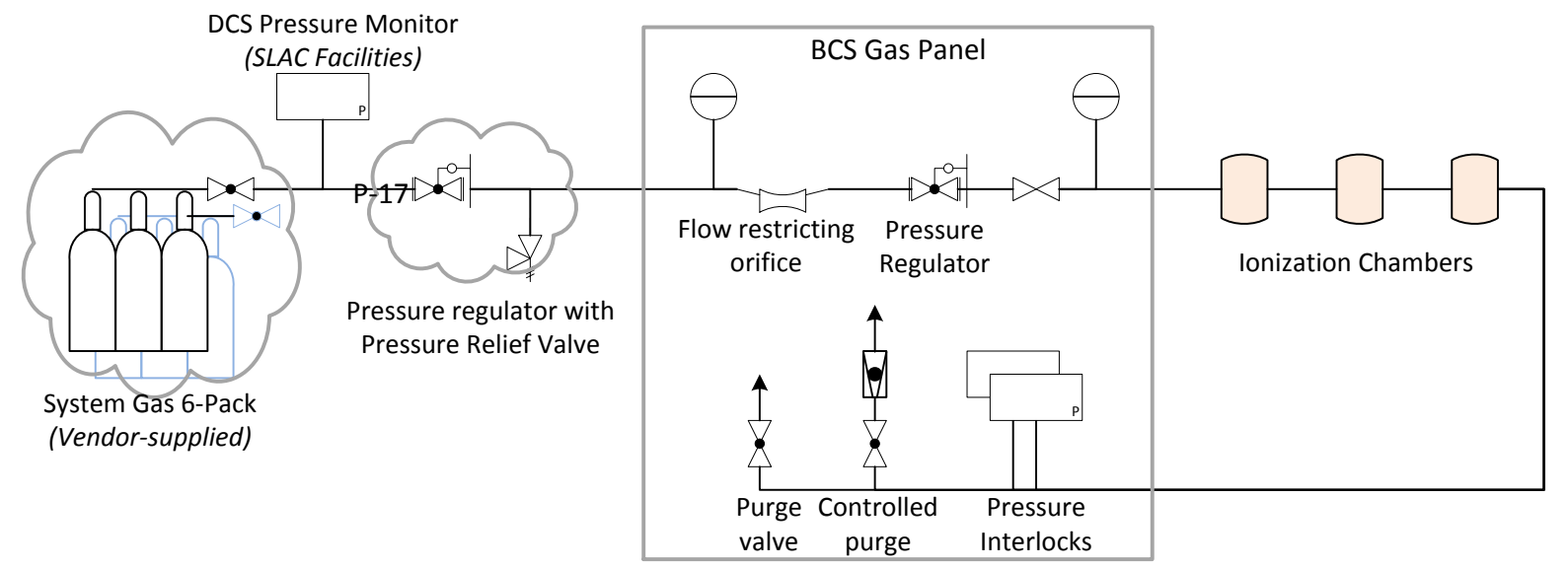

Figure 1: BCS Gas System - Single Line Diagram

\section{Review of BCS Ionization Chambers at SLAC:}

Two types of BCS ionization chambers are deployed at SLAC. These are:

- Protection Ion Chambers (PICs)

- $\quad$ Long Ion Chambers (LIONS).

\section{The PIC chamber}

The detection elements ${ }^{2}$ consist of 32 parallel plates inside a stainless steel can. One set of plates are positively charged at about 200 volts. The other set of plates is monitored by an electrometer/discriminator capable of being adjusted to provide a fault signal if the current increases above a predetermined level.

\footnotetext{
${ }^{2}$ SLAC Drawing AD-900-681-00
} 


\section{SLAC

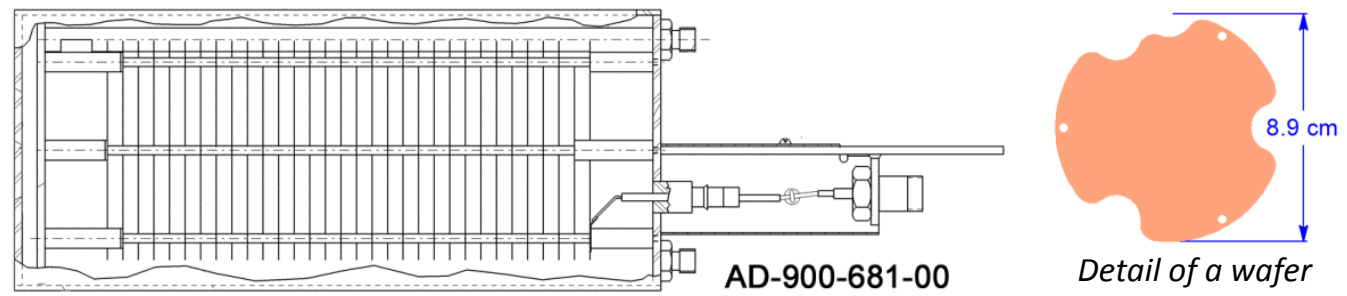

Figure 2: Detail of the PIC collector plates

The effective collection area is approximately 1.1 liters $^{3}$ and the gradient is 325 volts $/ \mathrm{cm}$. PIC chambers are operated open to the environmental air, gas filled with a mixture of five percent carbon dioxide balance argon or with helium ${ }^{4}$. When filled with a gas, the operating pressure is typically 8 pounds per square inch (PSIG) above atmospheric pressure.

\section{The LION chamber}

The LION detector ${ }^{5}$ consists of a length of 1-5/8 inch $50 \mathrm{ohm}$ air-filled RG 319/U (or equivalent ${ }^{6}$ ) coaxial cable. The center conductor is positively charged at 250 volts and the power supply is grounded through an electrometer/discriminator capable of being adjusted to provide a fault signal if the current increases above a predetermined level.

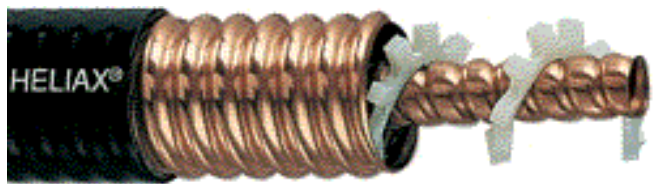

Figure 3: Cutaway photograph of a LION chamber

The nominal diameter of the outer conductor is $4.12 \mathrm{~cm}(1-5 / 8$ ") with an inner conductor of $1.9 \mathrm{~cm}$. The collection area is 1.1 liters per meter of length. LION chambers are often much longer than the dimension of a beam shower and thus the effective collection volume may vary in the range of two to ten or more liters. LION chambers are gas filled with five percent carbon dioxide balance argon. The operating pressure is typically 8 pounds per square inch (PSIG) above atmospheric pressure.

The field gradient in the LION operating at 250 volts varies with radius within the chamber between 150 and 350 volts per $\mathrm{cm}$.

\footnotetext{
${ }^{3}$ The space between the parallel plates is considered the active ion collection area.

${ }^{4}$ Five percent carbon dioxide balance argon is the most common gas. Helium gas generates less current in the presence of radiation than most other gases and has been used to support experimental programs with unusually high radiation levels.

${ }^{5}$ Zdarko, Richard, "LIONs at the Stanford Linear Accelerator Center”, January 1998. SLAC-PUB-7691.

${ }^{6}$ Commscope brand Andrew HJ7-50A is representative of the cable used in LION chambers.
} 


\section{SLAC

Gas-filled Coax. 1-5/8" at 250 volts

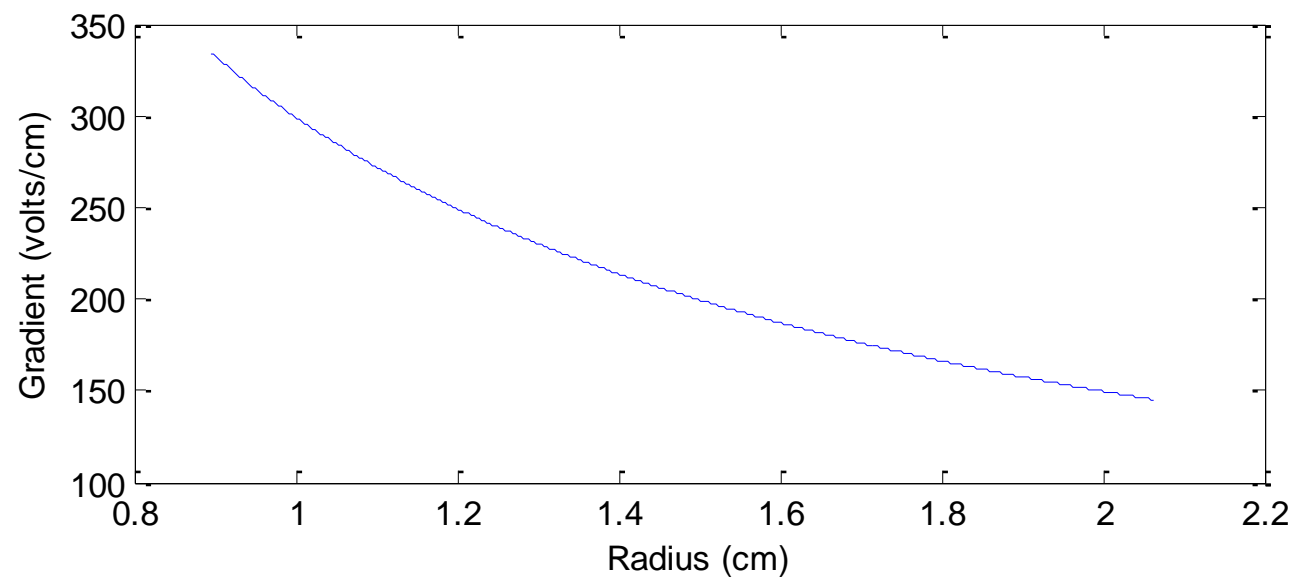

Figure 4: Electric field of a LION chamber

\section{Considerations in the choice of gas:}

Ion chambers have successfully operated using a wide variety of gases. Wilhelm Röntgen and Paul Ulrich Villard used air in their initial work in the late 1800's and it is from this legacy the Röntgen (a precursor to the Rad and the Rem) is derived. Modern detectors tend to use gases with higher purity and lower chemical reactivity, although air is still in use. Several of the features considered in the choice of gas for use in ionization chambers are:

- Human toxicity, including asphyxiation potential.

- Chemically inert to prevent oxidation of collection surfaces.

- Does not capture electrons easily (non-electronegative).

- Does not exhibit gas multiplication at operation point.

- Provides sufficient signal.

- Easily available and low operating cost.

\section{Signal strength and gas choice:}

The properties of several gases are shown in Table 1 with the signal shown for a single minimum-ionizing electron passing through the active region of the detector. Table 1 is based on operating at $150 \%$ of normal sea-level pressure. The "W-value" relates the ionization energy loss to the number of ion pairs created within the gas.

Table 1: Ion-pair production in ionization chamber gases

\begin{tabular}{|c|l|l|l|l|l|}
\hline Gas & $\begin{array}{l}\text { Minimum } \\
\text { Ionization Loss }\end{array}$ & $\begin{array}{l}\text { Density } \\
\text { @ 7.5 PSIG }\end{array}$ & $\begin{array}{l}\text { Energy loss } \\
\text { per distance }\end{array}$ & W-Value & $\begin{array}{l}\text { Ion-pairs per } \\
\text { distance @ 7.5 PSIG }\end{array}$ \\
\hline Helium & $1.9 \mathrm{MeV} \mathrm{cm} / \mathrm{g}$ & $2.5 \mathrm{e}-4 \mathrm{~g} / \mathrm{cm}^{3}$ & $483 \mathrm{eV} / \mathrm{cm}$ & $41.3 \mathrm{eV} /$ ion-pair & 12 Ion-pairs/cm \\
\hline Nitrogen & $1.8 \mathrm{MeV} \mathrm{cm} / \mathrm{g}$ & $1.7 \mathrm{e}-3 \mathrm{~g} / \mathrm{cm}^{3}$ & $3060 \mathrm{eV} / \mathrm{cm}$ & $34.8 \mathrm{eV} /$ ion-pair & 88 Ion-pairs $/ \mathrm{cm}$ \\
\hline Argon & $1.5 \mathrm{MeV} \mathrm{cm} / \mathrm{g}$ & $2.5 \mathrm{e}-3 \mathrm{~g} / \mathrm{cm}^{3}$ & $3735 \mathrm{eV} / \mathrm{cm}$ & $26.4 \mathrm{eV} /$ ion-pair & 141 Ion-pairs $/ \mathrm{cm}$ \\
\hline Air (dry) & $1.8 \mathrm{MeV} \mathrm{cm} / \mathrm{g}$ & $1.7 \mathrm{e}-3 \mathrm{~g} / \mathrm{cm}^{3}$ & $3060 \mathrm{eV} / \mathrm{cm}$ & $33.8 \mathrm{eV} /$ ion-pair & 91 Ion-pairs/cm \\
\hline $\begin{array}{c}\text { Carbon } \\
\text { Dioxide }\end{array}$ & $\sim 1.6 \mathrm{MeV} \mathrm{cm} / \mathrm{g}$ & $2.8 \mathrm{e}-3 \mathrm{~g} / \mathrm{cm}^{3}$ & $4500 \mathrm{eV} / \mathrm{cm}$ & $33 \mathrm{eV} /$ ion-pair & 136 Ion-pairs/cm \\
\hline
\end{tabular}

${ }^{7}$ http://pdg.lbl.gov/2012/AtomicNuclearProperties/HTML_PAGES/007.html, retrieved 26 August, 2012

${ }^{8}$ Knoll GF, "Radiation Detection and Measurement", $2^{\text {nd }}$ edition, 1989. 
As noted in the right-hand column, excepting for Helium, the number of ion pairs created in a chamber of a given geometry is relatively independent of the choice of gas. The gas mixture or five percent carbon dioxide balance argon (traditionally used at SLAC) will provide slightly higher signals than achieved in air or nitrogen. From a signal strength perspective, Argon/CO2 is considered to be a satisfactory choice.

\section{Chemical properties of gases}

Helium and Argon, both noble gases, are generally considered to be chemically inert.

Nitrogen, in the presence of high levels of ionizing radiation, can combine with trace oxygen to form nitric oxide, or with trace water vapor to form nitric acid. Nitric oxide and nitric acid are both chemically reactive materials that attack a wide variety of metals. At the ionization levels typically found in protective ion chambers, the generation of nitrogen compounds is not a significant concern. Nitrogen gas (without impurities) can oxidize materials, generating a layer of <host-material >-nitride. At room temperature, generation of nitrides is not a significant concern.

Air is predominately composed of nitrogen, and the chemical issues associated with nitrogen apply to the use of air. Air contains oxygen which will oxidize aluminum. Atmospheric air contains water which will react with metals to create hydrates of metals and of metallic oxides. Compressed air distributed throughout SLAC is typically quite dry and clean, however the possibility exists of a compressor malfunction or failure in the drier systems which can include oil or dust contaminants. There is very little experience in using air as an ionization chamber gas at SLAC and members of the committee expressed concerns regarding the use of air in BCS chambers.

Carbon dioxide may dissociate in the presence of ionizing radiation or ultraviolet light. Free carbon ions have the potential of chemically reacting with exposed metal surfaces to form metallic carbides or carbenes. At the ionization levels typically found in protective ion chambers, the generation of carbon compounds is not a significant concern.

\section{Electron multiplication in gases}

The Townsend threshold for the gases considered is not available for the geometry and pressures under consideration. Threshold electric field strengths vary by gas species and impurity. Values in the range of 100 $\mathrm{kV} / \mathrm{cm}$ to several MV/cm are typical values ${ }^{10}$. The PLIC and the LION chambers operate at $350 \mathrm{~V} / \mathrm{cm}$ or less. The choice of gas does not appreciably affect the proportional chamber (gas multiplication) threshold.

\section{Toxicity of gases}

The gas used in ionization chambers can generate oxygen deficiency hazards in the event of a line rupture in a modest-volume well sealed space. Table 2 lists the threshold volumes for a discharge into a 10 foot by 10 foot by 10 foot area.

The most commonly adopted mitigation or hazard reduction for the use of an oxygen displacing gas is to limit the maximum flow rate using an orifice ${ }^{11}$ sized to restrict the maximum available flow to slightly above the highest flow required. Naturally occurring air exchange rates will generally mitigate any toxicity or oxygen deficiency hazards if the maximum flow rate is sufficiently reduced.

\footnotetext{
${ }^{9}$ Sauli, Fabio, "Instrumentation in High Energy Physics", 1993. Adapted from Section 4.1 Table 2 with linear corrections for pressure.

${ }^{10}$ Knoll, ibid. Data from example and extrapolated from graphs.

${ }^{11}$ The use of a 0.020 inch orifice between the supplied argon/CO2 at 20 psig and the instrumentation regulator limiting pressure to 8 psig will limit Argon gas flow to approximately 4 cubic feet per hour.
} 
Table 2: Toxicity of ionization chamber gases

\begin{tabular}{|c|c|c|}
\hline Gas & Characteristics & Threshold quantities for a hazardous exposure. \\
\hline Helium & $\begin{array}{l}\text { Helium density is } 14 \% \text { that of } \\
\text { air. A spill can present hazards } \\
\text { in ceiling spaces. }\end{array}$ & $\begin{array}{l}\text { Helium is difficult to mix with building air due to its low } \\
\text { density. In most circumstances, helium leaks out before a } \\
\text { generalized oxygen deficiency hazard can develop. }\end{array}$ \\
\hline Nitrogen & $\begin{array}{l}\text { Density approximately equal to } \\
\text { air. }\end{array}$ & $\begin{array}{l}70 \text { cubic feet of nitrogen, completely mixed into } 1,000 \\
\text { cubic foot volume, will create an ODH hazard. Localized } \\
\text { hazards can develop with lower volumes of oxygen } \\
\text { displacing gas. }\end{array}$ \\
\hline $\begin{array}{l}\text { Argon (including } \\
\text { Argon/CO2) }\end{array}$ & Density $50 \%$ greater than air. & $\begin{array}{l}70 \text { cubic feet of argon, completely mixed into } 1,000 \text { cubic } \\
\text { foot volume, will create an ODH hazard. Localized } \\
\text { hazards can develop with lower volumes of oxygen } \\
\text { displacing gas. } \\
\text { If gas is rapidly spilled without introducing significant } \\
\text { mixing, } 50 \text { cubic feet in a } 100 \text { square foot area can } \\
\text { produce an oxygen-free layer } 6 \text { inched deep. }\end{array}$ \\
\hline Air & No hazards & \\
\hline $\begin{array}{l}\text { Carbon Dioxide } \\
(\mathrm{CO} 2)\end{array}$ & $\begin{array}{l}\mathrm{CO} 2 \text { is a toxic gas. } \\
\text { Short Term Exposure Limit } \\
\text { (STEL) is } 3 \% \text { by volume. } \\
\text { Time Weighted Average (TWA) } \\
\text { limit is } 0.5 \% \text { by volume. }\end{array}$ & $\begin{array}{l}\text { Oxygen deficiency hazards develop before exposure at } \\
\text { STEL thresholds can exist. }\end{array}$ \\
\hline
\end{tabular}

\section{Gas Exchange Rates}

Ionization chamber detector sensitivity is maintained at a more constant level by flowing the gas at a low replacement rate than by flushing and sealing the system. Experience from chambers in high dose environments at SLAC indicates that one gas change per month is sufficient to maintain detector sensitivity ${ }^{12}$.

BCS system designs with one change per week include an adequate safety margin while being a practical and economical minimum flow rate.

\section{Exercise: Calculate the gas change rate of a medium sized BCS system.}

Given a BCS system with 10 PIC chambers and 40 meters of 1-5/8 inch LION detector cable:

- $\quad$ Each PIC can has a volume of 2.5 liters $=0.09$ cubic feet. 10 chambers $=0.9$ cubic feet.

- Each meter of LION cable has a volume of 1.0 liter $=0.04$ cubic feet. 40 meters $=1.6$ cubic feet

- Pressurized at 8 PSIG (1.54 atmospheres), 2.5 cubic feet volume contains 3.85 cubic feet of gas at atmospheric pressure.

Provide a gas flow rate of 0.1 cubic feet per hour ( $\mathrm{SCFH})$. This is the lowest flow rate measurable by the commonly available rotameters.

- $\quad 0.1 \mathrm{SCFH}=16.8$ cubic feet per week

With the above BCS detector system (10 PICs, 40 meter LION):

\footnotetext{
${ }^{12}$ Clive Fields, Email communication 09/13/2012. "It is known that chambers used in E-158 were able to run in dose levels gigarad per month with a change in gas (nitrogen) every approx 3 hours. Assuming that the loss in sensitivity is $\sim$ linear in the ionization dose to the gas, that the BCS chambers do not operate above $50 \mathrm{krad}$ per month ( 10 times the levels at FACET), but that $\sim 10$ chambers are in series, then gas exchange every month should be satisfactory."
} 
- $\quad$ 16.8 SCFWeek / 3.85 cubic feet $=4.4$ gas changes per week.

A minimum flow rate easily exceeds the target gas change rate.

\section{Response to Ionizing Radiation}

\section{First exercise:}

Repeat Röntgen's work. One cubic centimeter of air exposed to one Roentgen of radiation ${ }^{13}$.

Start with the volume of gas:

- Volume: $1\left[\mathrm{~cm}^{\wedge} 3\right]$

Of dry air at $0 \mathrm{C}$ and $101 \mathrm{kPa}$ :

- Mass of gas: $1\left[\mathrm{~cm}^{\wedge} 3\right] * 1.293 \mathrm{e}-3\left[\mathrm{~g} / \mathrm{cm}^{\wedge} 3\right]=1.293 \mathrm{e}-3[\mathrm{~g}]$

And exposed to 1 Roentgen of ionizing radiation (one Roentgen in air is $0.877 \mathrm{Rad}$ ):

- $\quad 1 \mathrm{Rad}=1 \mathrm{e}-2 \mathrm{~J} / \mathrm{kg}$ (by definition)

- 1 Roentgen $=0.877 \mathrm{Rad}=8.77 \mathrm{e}-3[\mathrm{~J} / \mathrm{kg}]=8.77 \mathrm{e}-6[\mathrm{~J} / \mathrm{g}]$

The energy deposited in the gas is:

- $\quad$ Energy deposition $=1.293 \mathrm{e}-3[\mathrm{~g}] * 8.77 \mathrm{e}-6[\mathrm{~J} / \mathrm{g}]=1.13 \mathrm{e}-8[\mathrm{~J}]$

The energy required to liberate ion pairs in air is:

- $\quad 33.8 \mathrm{eV} /$ ion-pair $\rightarrow$ 2.96e-2 ion-pairs/eV $\rightarrow 2.96 \mathrm{e}-2 \mathrm{C} / \mathrm{J}$

Thus the predicted charge from a cubic-centimeter volume of dry air exposed to one Roentgen is:

- $\quad 1.13 \mathrm{e}-8[\mathrm{~J}] * 2.96 \mathrm{e}-2[\mathrm{C} / \mathrm{J}]=3.35 \mathrm{e}-10[\mathrm{C}]$

The expected answer is $1 \mathrm{esu}=\approx 3.33564 \mathrm{e}-10[\mathrm{C}]$

\section{Second exercise:}

Calculate the response of a pressurized Ar-filled PIC to ionizing radiation.

Start with the volume of a PIC:

- Volume of a PIC: $1.1 \mathrm{e} 3\left[\mathrm{~cm}^{\wedge} 3\right]$

Pressurized to 7.5 PSIG Argon

- Mass of gas: $1.1 \mathrm{e} 3\left[\mathrm{~cm}^{\wedge} 3\right] * 2.5 \mathrm{e}-3\left[\mathrm{~g} / \mathrm{cm}^{\wedge} 3\right]=2.75[\mathrm{~g}]$

And exposed to $1 \mathrm{Rad} / \mathrm{hr}$ of ionizing radiation:

- $1 \mathrm{Rad} / \mathrm{hr}=1 \mathrm{e}-2 \mathrm{~J} / \mathrm{kg}-\mathrm{hr}($ by definition $)=1 \mathrm{e}-5[\mathrm{~J} / \mathrm{g}-\mathrm{hr}] * 1 / 3600[\mathrm{hr} / \mathrm{s}]=2.778 \mathrm{e}-9[\mathrm{~J} / \mathrm{g}-\mathrm{s}]$

The energy deposited in the gas from the passage of the ionizing particles is:

- $\quad$ Energy deposition $=2.75[\mathrm{~g}] * 2.78 \mathrm{e}-9[\mathrm{~J} / \mathrm{g}-\mathrm{s}]=7.65 \mathrm{e}-9[\mathrm{~J} / \mathrm{s}]$

The energy required to liberate ion pairs in Argon is:

- 26.4 eV/ion-pair $\rightarrow 3.8 \mathrm{e}-2$ ion-pairs/eV $\rightarrow 3.8 \mathrm{e}-2 \mathrm{C} / \mathrm{J}$

Thus the current from an argon-pressurized PIC exposed to $1 \mathrm{Rad} / \mathrm{hr}$ of ionizing radiation is:

- $\quad 7.65 \mathrm{e}-9[\mathrm{~J} / \mathrm{s}] * 3.8 \mathrm{e}-2[\mathrm{C} / \mathrm{J}]=0.29 \mathrm{e}-9[\mathrm{C} / \mathrm{s}]=0.29 \mathrm{e}-9[\mathrm{~A}]=290[\mathrm{pA}]$

The above calculation is based on an "air-equivalent" ion chamber. The PIC chamber has a steel can which will generate additional ionizing charges from photon interactions with the can. The calculation additionally ignores any ion-pair recombination, edge effects, etc.

${ }^{13}$ http://en.wikipedia.org/wiki/Rontgen, retrieved 05 Sept 2012 